\title{
OS IMPACTOS DO PROGRAMA "MINHA CASA MINHA VIDA" NA CIDADE PONTA DE PEDRAS-PARÁ
}

\section{Tatiana da Silva Prado ${ }^{1}$ Sandra Maria Fonseca da Costa ${ }^{2}$}

Resumo - O Programa Minha Casa Minha Vida tem despertado o interesse, desde o início de sua implantação, para o risco da segregação socioespacial. Alguns pesquisadores apontam impactos da produção desses empreendimentos, principalmente em função da localização, pois o direito à cidade não é garantido, em função do acesso à infraestrutura e aos serviços, os quais são, muitas vezes, inexistente ou precário. Desde a criação do Banco Nacional de Habitação (BNH), a questão habitacional no Brasil sempre foi tratada pelo olhar quantitativo, resumindo-se a números. Nesse sentido, esse artigo tem o objetivo de analisar o processo de pós-ocupação do PMCMV I, localizado na cidade de Ponta de Pedras, Ilha do Marajó, Pará. Para esta análise foram aplicados formulários aos moradores dos Loteamentos do PMCMVI.

Palavras-chave: Programa Minha Casa Minha Vida; Habitação; Amazônia; Segregação socioespacial.

\footnotetext{
1 Geografia/Universidade do Vale do Paraíba, Brasil. E-mail: tatipradouba@gmail.com.

${ }^{2}$ Geografia/Universidade do Vale do Paraíba, Brasil. E-mail: sandra@univap.br.
} 